\title{
Impactos socioeconômicos de uma doença emergente
}

\author{
Socioeconomic impacts of an emerging disease
}

\author{
Márcia Grisotti ${ }^{1}$ \\ Fernando Dias de Ávila-Pires ${ }^{2}$
}

${ }^{1}$ Programa de Pós-Graduação em Sociologia Política/CFH.

Campus Universitário Trindade, Caixa Postal 476. 88040-900. Florianópolis SC ppgsp@cfh.ufsc.br

${ }^{2}$ Programa de Pós-Graduação em Saúde Pública, Núcleo de Ecologia Humana e Saúde, Universidade Federal de Santa Catarina.

\begin{abstract}
In 1955 a population explosion of the slug Sarasinula linguaeformis (Semper, 1885) damaged crop plantations in the municipalities of Nova Itaberaba and Planalto Alegre, western of Santa Catarina State, Brazil. In this article we analyze the socioeconomic impacts caused by the emergence of this plague, which raised the suspicion, eventually confirmed, of the occurrence of human cases of abdominal angyostrongiliasis. The data were collected through the observation of a serological study during the period of August 2000 to August 2001 by a research team from the Catholic University of Rio Grande do Sul (PUCRS) together with field technicians from the Empresa de Pesquisa Agropecuária e Extensão Rural de Santa Catarina S.A. (Epagri-SC), and with the members of 50 local families. In order to analyze these impacts, we elaborated several analytical categories as economic losses; preventive measures, habit change and social prejudice, that emerged from the narratives of the residents interviewed. It became evident the need for sociological analyses of epidemiological problems, in addition to strictly medico-sanitary considerations.
\end{abstract}

Key words Abdominal angiostrongyliasis, Socioeconomic impacts, Slugs, Risk perception, Santa Catarina
Resumo Em 1995, ocorreu uma praga de lesmas identificadas como Sarasinula linguaeformis (Semper, 1885), que prejudicou as lavouras situadas entre os municípios de Nova Itaberaba e Planalto Alegre, no oeste do estado de Santa Catarina, Brasil. Neste artigo analisamos os impactos socioeconômicos provocados pela ocorrência desta praga, que sinalizou a possibilidade, posteriormente verificada, da emergência de casos de angiostrongilíase abdominal. Os dados foram coletados através de observação do estudo soroepidemiológico realizado na região durante o período de agosto de 2000 a agosto de 2001 pela equipe de pesquisa da Pontifícia Universidade Católica do Rio Grande do Sul (PUCRS), entrevistas com técnicos da Empresa de Pesquisa Agropecuária e Extensão Rural de Santa Catarina S.A. (Epagri-SC) e com cinquenta famílias locais. Para avaliar esses impactos, elaboramos algumas categorias de análise, como: prejuízo econômico; medidas preventivas e mudança de hábitos; estigma e preconceito, que surgiram à luz das narrativas dos sujeitos entrevistados. Ficou evidente a necessidade de se procederem a estudos sobre os aspectos sociológicos dos problemas epidemiológicos, além dos estritamente médico-sanitários.

Palavras-chave Angiostrongilíase abdominal, Impactos socioeconômicos, Lesmas, Percepção de risco, Santa Catarina 


\section{Introdução}

Em 1958, o ecólogo Charles Elton ${ }^{1}$ reuniu os relatos disponíveis sobre as alterações nos padrões de distribuição geográfica das espécies na biosfera, ocorridas ao longo do tempo. Para ilustrar os eventos, datados de tempos históricos, selecionou sete exemplos de introdução voluntária e involuntária e de suas consequências desastrosas. A ausência ou ineficiência de predadores locais e os hábitos peculiares da espécie invasora, especialmente as que têm a estratégia de "reprodução-r", são responsáveis pela explosão populacional que as transforma rapidamente em pragas.

O tema fora bem explorado por Marston Bates $^{2}$ no que se refere a organismos causadores de doenças e retomado, recentemente, por Crosby ${ }^{3,4}$, que descreveu a introdução de espécies a partir da Europa, durante o processo de colonização dos demais continentes.

No Brasil, a Lei de Proteção à Fauna (nº 5.197, de 3/1/1967) determina, em seu artigo $4^{\circ}$, que Nenhuma espécie poderá ser introduzida no País sem parecer técnico oficial favorável e licença expedida na forma da Lei. Este dispositivo prevê a implantação de um sistema eficiente de vigilância que previna a importação propositada de espécies exóticas e que evite a imigração/introdução de espécies indesejáveis, que podem revelar-se pragas de produtos agrícolas ou responsáveis por doenças que afetem animais e plantas, incluindo o homem. Infelizmente, ele nem sempre é cumprido.

Os estudos e as medidas institucionais de controle de espécies exóticas proposital ou acidentalmente introduzidas centram seu foco de atenção na busca de métodos eficazes e no mapeamento de seus impactos sobre a saúde humana, animal e dos vegetais cultivados, negligenciando, muitas vezes, os aspectos socioculturais e econômicos envolvidos no processo. Neste artigo, analisamos os impactos socioeconômicos e sanitários provocados pela emergência de lesmas como praga agrícola e como vetores de doenças emergentes na comunidade da Linha Cumbucica, que se situa em parte no município de Nova Itaberaba e em parte no de Planalto Alegre, oeste do estado de Santa Catarina. Os dados foram coletados através de observação do estudo soroepidemiológico realizado na região durante o período de agosto de 2000 a agosto de 2001 pela equipe de pesquisa da Pontifícia Universidade Católica de Porto Alegre (PUCRS), com técnicos da Empresa de Pesquisa Agropecuária e Extensão Rural de Santa Catarina S.A. (Epagri-SC) e de entrevistas com cinquenta famílias locais. Para analisar esses impactos ela- boramos algumas categorias de análise, como prejuízo econômico; medidas preventivas e mudança de hábitos; estigma e preconceito, que surgiram à luz das narrativas dos sujeitos entrevistados.

\section{Lesmas como praga de plantas cultivadas}

Em 1995, lavouras situadas entre os municípios de Nova Itaberaba e Planalto Alegre, no oeste do estado de Santa Catarina, Brasil, foram invadidas pelo molusco terrestre Sarasinula linguaeformis (Semper, 1885) conforme relato de Laitano et al. ${ }^{5}$. Além dos prejuízos causados à agricultura, os proprietários rurais, que tiveram suas casas, jardins, chiqueiros e galinheiros invadidos, sofreram discriminação por parte dos habitantes de municípios vizinhos e viram suas propriedades se desvalorizarem. Essas lesmas são hospedeiros intermediários potenciais de um nematódeo, Angiostrongylus costaricensis ${ }^{6}$, agente da angiostrongilíase abdominal ${ }^{7,8}$.

Em 1999, as autoridades municipais solicitaram o auxílio da Empresa de Pesquisa Agropecuária e de Extensão Rural de Santa Catarina S.A. (Epagri), que por sua vez recorreu ao Instituto de Biociências da Pontifícia Universidade Católica do Rio Grande do Sul (PUCRS).

A área infestada (1.500 hectares) compreendia a comunidade da Linha Cumbucica, que pertence em parte ao município de Nova Itaberaba (67 famílias) e em parte ao município de Planalto Alegre (sete famílias), totalizando 74 famílias (75 em 1997), com uma média de cinco pessoas por residência. A população é, basicamente, de origem italiana, vivendo em propriedades de aproximadamente 12 hectares $(120.000 \mathrm{~m} 2)$.

A região caracteriza-se pelo relevo acidentado e agricultura de pequenas propriedades, com utilização de mão-de-obra familiar e de tração animal. As culturas típicas são o milho e o feijão, cultivados em sistema singular (solteiro) na safra e safrinha, ou em consórcio (principalmente consórcio de substituição); e, com menor expressão, a soja - consorciada com milho9 ${ }^{9}$ O restante é produção de subsistência, com exceção de algumas famílias que produzem fumo, embora seja preciso registrar que esse cultivo tem aumentado, em razão do preço e da praticamente inexistente perda da lavoura, devido ao uso de agrotóxicos.

Existem também, na região, aproximadamente quinze aviários construídos segundo um modelo padrão, financiados pelos próprios agricultores, os quais também são responsáveis pela manutenção das edificações e dos equipamentos 
exigidos pelas empresas. Essa forma de produção conjunta é chamada de "integração".

Como foi publicado no jornal Agropecuária Catarinense $^{10}$, na Epagri não havia registro de ocorrência de lesmas como praga na cultura de feijão em Santa Catarina anterior à safra de 94/ 95, cuja "área de ataque" foi de aproximadamente 150 hectares. Chiaradia e Milanez ${ }^{11}$ relatam que alguns espécimes foram enviados ao malacologista José Wilibaldo Thomé ${ }^{12}$ (PUCRS), que identificou a espécie.

As lesmas são encontradas em abrigos naturais tais como bordas de matas ou capoeiras, montes de palha, patamares de pedras, e no meio do "milho dobrado". Além dos danos à agricultura, os moradores destacavam a preocupação com a invasão das lesmas nas residências e no peridomicílio.

Sobre as tentativas de combate à praga, agrônomos da Epagri mencionaram, em 1999, que seu controle, utilizando-se inimigos naturais potenciais, predadores ou parasitos, não havia apresentado a eficácia necessária, mas que pesquisas com algumas substâncias químicas se mostravam promissoras ${ }^{11}$. O informante da Epagri considera que é difícil monitorar os hábitos desse molusco, pois eles preferem as horas mais amenas $e$, por isso, eles andam mais à noite e madrugada; eles, às vezes, se enterram e permanecem vários dias até que condições climáticas favoreçam para eles saírem novamente. Enquanto isso, os agricultores da região atingida tentavam proteger suas hortas do ataque das lesmas, espalhando cal ao redor dos canteiros.

Para explicar o aparecimento das lesmas, os pesquisadores da Epagri respondiam, inicialmente, que elas encontraram um ambiente favorável, sem predadores ou inimigos naturais e que, mesmo que existissem, o controle natural não seria suficiente para manter a população reduzida. Além disso, as práticas de conservação do solo que foram implementadas na região nos últimos anos criaram condições propícias de abrigo e alimento, visto que elas consomem carboidratos e proteínas de vegetais verdes, secos ou em decomposição. Entretanto, as respostas dadas pelos moradores durante as entrevistas sobre as possíveis causas do aparecimento das lesmas indicam que a explicação dada posteriormente pela Epagri foi a mais convincente. Uma vez que aquela espécie era, até então, reportada desde São Paulo até as regiões Norte e Nordeste, tudo levava a crer que fosse exótica e que havia sido introduzida acidentalmente na região, principalmente através de mudas de flores e frutas.

\section{Lesmas como hospedeiros de Angiostrongylus}

Do ponto de vista médico, a angiostrongilíase abdominal é uma doença cujos sintomas são vagos, para a qual não existe tratamento e da qual, na maior parte dos casos, só se tem o diagnóstico quando se isola o parasito, ou através de sorologia que indica a infecção, mas não a doença. O teste sorológico pode apresentar reação cruzada com outros parasitos, e o uso de antihelmínticos pode provocar a migração do parasito para outros órgãos do corpo. As manifestações clínicas ocorrem numa região do organismo onde os sintomas podem-se confundir com os de outras doenças, especialmente apendicite e tumores. Trata-se, aqui, de um parasito intestinal acidental, cujos ovos não são eliminados nas fezes do hospedeiro humano, ao contrário de outras helmintíases como esquistossomose e oxiuríase. Além disso, é uma doença considerada como subdiagnosticada devido à ausência de diagnóstico sorológico específico e sensível; à ausência de larvas nas fezes humanas; ao não envio de muitas peças cirúrgicas, especialmente aquelas diagnosticadas clinicamente como apendicite, para estudo anatomopatológico, por serem descartadas em curto prazo, quando analisadas, e ao desconhecimento da doença entre clínicos em geral ${ }^{13}$.

Os trabalhos de pesquisa de especialistas ${ }^{13-18}$ foram essenciais para elucidar o ciclo biológico de A. costaricensis no Brasil. Baseados nessa literatura, técnicos da Epagri difundiram a informação de que a forma infectante do parasito, liberada através do muco secretado pelas lesmas, poderia infectar pessoas pela ingestão de produtos hortifrutigranjeiros contaminados. Os problemas socioeconômicos decorrentes desta declaração serão analisados mais tarde. No momento é importante notar que, antes mesmo da verificação da existência de lesmas infectadas, já se cogitava da possibilidade de ocorrência de casos de angiostrongilíase abdominal, tendo sido divulgadas as suas características e sintomas, o ciclo de vida do parasito e seus hospedeiros, e medidas profiláticas que deveriam ser adotadas. Neste último aspecto, alertava-se para o fato de que as larvas resistiam a certo de grau de ressecamento e que o vinagre favorecia a contaminação, já que ativava a larva, o que representava um problema de saúde pública tanto para a população residente em áreas infestadas quanto para consumidores de produtos hortifrutigranjeiros provenientes daquela região. 
Foram enviados exemplares de lesmas para análise na PUCRS e constatou-se, em julho de 1999, que $86 \%$ das lesmas coletadas estavam contaminadas. Nesse período, os agricultores foram forçados a evitar o plantio de certas culturas devido à preferência alimentar dos moluscos por aquelas culturas; segundo informante da Epagri, três famílias haviam abandonado suas propriedades.

Se as lesmas estavam infectadas, era possível que a população humana também estivesse. A partir daí, os dois pesquisadores, o da PUCRS e o da Epagri/SC, programaram um calendário para a coleta de moluscos e de sangue - na população humana, a cada quatro meses, até completar quatro coletas (agosto/2000, dezembro/ 2000, abril/2001 e agosto/2001). Em todos os períodos de coleta os procedimentos eram os mesmos: palestras do médico e do representante da Epagri, entrega dos resultados sorológicos, inquérito clínico-epidemiológico para os que tinham resultado positivo e nova coleta de sangue.

Em agosto de 2000 foi realizada a primeira coleta em moradores da área atingida, bem como nova coleta de moluscos. Simultaneamente, os pesquisadores alertaram os médicos e profissionais de saúde da região para o problema. Nesse período, foi realizada uma palestra com a presença do médico da PUCRS acompanhado por dois parasitologistas da Universidade de Akita, no Japão, com o qual a PUC mantinha um convênio, e da Epagri.

Essas atividades foram amplamente divulgadas pela imprensa. No dia 15 de agosto de 2000 , por exemplo, um jornal de grande circulação em Santa Catarina ${ }^{19}$ publicou, com amplo destaque na página principal, informações sobre as tentativas, tanto da PUCRS quanto da Epagri, em desenvolver um meio para combater as lesmas e a doença e um parecer sobre a importância da angiostrongilíase: o verme, de dois centímetros e em forma de um fio de cabelo, ao ser ingerido por seres humanos se aloja nos vasos sanguíneos do intestino, provocando inflamação e perfuração das paredes do órgão, infecção generalizada e obstrução do intestino (Diário Catarinense, 15/08/2000) ${ }^{19}$.

Cinco meses depois, já com os resultados da primeira sorologia, o jornal local Cooperalfa ${ }^{20}$, editado em Chapecó (SC), divulgou o depoimento do médico responsável pela pesquisa: "pode-se ter vários infectados, mas bem poucos doentes". Segundo ele, $24 \%$ das pessoas da comunidade estavam infectadas com o "verme", mas em nenhuma doença intestinal havia se manifestado.

$\mathrm{Na}$ segunda coleta foram divulgados pela imprensa os resultados sorológicos, mas o des- taque foi-se reduzindo ao longo dos meses, em face das consequências que as informações geravam. Se, por um lado, serviam para alertar a população atingida, as regiões vizinhas e os consumidores de hortifrutigranjeiros para o problema, e para demonstrar a relevância médica e social da pesquisa e consequentemente auxiliar na obtenção de recursos financeiros, por outro criavam problemas sociais e econômicos para a população atingida. Faziam com que as pessoas e suas propriedades ficassem estigmatizadas ${ }^{21}$.

\section{Impacto socioeconômico}

O noticiário da imprensa originou efeitos adversos. As pessoas perceberam que os valores econômicos e simbólicos de suas terras e a venda de alguns produtos decaíram. Vários entrevistados relataram perdas, especialmente no cultivo de hortaliças, de milho e de feijão. Aliadas às perdas econômicas ocorreram mudanças de hábitos e adoção de medidas preventivas, muitas delas construídas através do resgate da tradição da comunidade em lidar, ao longo dos tempos e de forma empírica, com diferentes pragas agrícolas. Houve a emergência de estigma e preconceito nas comunidades vizinhas em relação aos afetados diretamente. Identificamos dois tipos de preconceito: o externo, no qual as pessoas de outras regiões deixaram de frequentar a comunidade; e o interno, no qual alguns membros da comunidade procuravam descobrir o responsável pelo problema.

De acordo com os entrevistados, a praga surgiu em 1994, após a introdução de mudas de laranjeiras trazidas do estado de São Paulo. Muitos optaram pela plantação de fumo por considerarem-na a única solução para eliminar as lesmas e pelo valor e incentivo que recebem das empresas contratantes; embora reconhecessem os problemas oriundos do uso, segundo eles necessário, de diversos agrotóxicos nesse tipo de cultura.

$\mathrm{Na}$ época, não foi realizada, por parte dos órgãos públicos responsáveis, uma estimativa do valor das perdas dos agricultores. No entanto, observou-se que diversos agricultores que haviam plantado feijão no ano em que o problema surgiu não voltaram a fazê-lo. Além disso, das 75 famílias que residiam na comunidade em 1997, restaram 59 em 2006. Não se pode dizer que a praga tenha sido responsável pela mudança das famílias, já que o êxodo rural tem ocorrido intensamente em toda a região, principalmente pela redução da renda na atividade agrícola, mas pode ter contribuído para aquela decisão. 
O problema das pragas agrícolas foi mencionado por vários entrevistados. Para eles, essas pragas terminam sozinhas. Lembraram que, em outras épocas, havia o gafanhoto, depois a lagarta, depois o pulgão que acabava com o trigo, como é ilustrado nos seguintes depoimentos:

Mas eu não sei não, cada vez tem mais pragas. O colono planta pouco e tudo o que é praga vai na planta, porque tem pouca planta. Antigamente tinha planta de tudo, agora o colono planta uma coisinha ali e vêm os ratos, as lesmas, a lagarta; esse ano a lagarta comeu quase todo o milho. É por isso que o colono acaba indo para a cidade! (M. M., 29 anos).

Do início ao fim da pesquisa, as lesmas permaneceram um problema. Os entrevistados relataram suas perdas, descreveram os hábitos das lesmas e o contato frequente que mantinham com os moluscos. O conhecimento da população sobre os hábitos dos moluscos auxiliou a equipe médica na busca ativa das lesmas, bem como elucidou algumas hipóteses sobre as possíveis fontes de contaminação, como a contaminação hídrica.

Hoje foi achado umas dez lesmas, dentro do banheiro. A gente acha na sujeira das folhas de eucalipto, na grama. Não dá mais feijão. Há dois anos atrás eu plantava abóbora, quando eu ia pegar era só o corpo da abóbora e dentro estava cheio de lesmas [...] Depois veio esse toque da doença (V. O., 43 anos).

No começo minha prima se desesperava. Ela dizia: "Nós vamos viver do quê? Elas estão comendo tudo!” Até o padre andou benzendo. Nós plantamos 3 mil e 500 pés de melancia, sobrou um pé. Terminou tudo. Elas roíam o caulezinho na terra (S. O., 43 anos).

Um dia, eu estava carpindo embaixo do parreiral e vi uma estradinha preta de lesma e um ninho de formigas cortadeiras. Elas se escondiam onde era mais fresco, lá onde tinha as formigas (L. R., 63 anos).

Um dia estava chovendo bastante e eu vi que elas estavam atravessando a água. Ai eu pensei: como elas podiam atravessar? [...] Vê a intenção, a inteligência desse bichinho, além de tudo. É um bichinho que dá para dizer que é nojento mesmo, só que é esperto ( V. O., 43 anos).

No verão ela aparece e no inverno ela se esconde. Elas se escondem onde tem umidade (C. G., 38 anos).

De manhã, quando eu levanto, eu sempre vejo algumas na parede. Mas eu nunca me toquei que fosse um inseto que incomodasse. [...] Uns me dizem que elas descem pela água, outras pelo carro. Aqui estavam desconfiando das fitas (madeiras) trazidas pelos caminhões (M. S., 68 anos).
Alguns relatos ilustram a desconfiança introduzida na rede de relações sociais:

Uma vez eu disse para um funcionário da Prefeitura de Nova Itaberaba: "Você é quem trouxe a lesma aqui para que a gente passasse a plantar só fumo nessa região; porque elas só morrem com o fumo, elas não comem o fumo." É, só assim, brincando. [...] Ela pode ter vindo, sabe da onde, de muito longe. Já se ouviu por outras pessoas que pode ser de mudas de árvores, de laranjeira (J. R., 60 anos).

Os donos das propriedades nas quais não havia infestação não percebiam o problema como deles e alguns sequer falavam sobre a doença. Mas os entrevistados que vivenciaram o problema mencionaram, na última etapa das entrevistas, a falta de solidariedade entre os moradores e argumentaram que, se a comunidade, incluindo o proprietário das terras onde havia se iniciado a infestação de lesmas, houvesse ajudado desde o início, provavelmente elas não teriam se alastrado. Um morador sugeriu a realização de mutirões para o combate das lesmas.

Embora as lesmas representassem a perda da safra de muitos produtos, esse não foi o único motivo para explicar a supressão de alguns cultivos. Nas declarações dos agricultores, é mencionado um fator mais estrutural que envolve a política agrícola brasileira:

Este ano, mesmo sem as lesmas, eu não estou plantando milho. Não está valendo mais nada, nada mesmo. É só prejuízo, porque o insumo, o preço da semente, a mão-de-obra, o maquinário, tudo isso não compensa (D. P., 61 anos).

O fumo, a firma vem e traz o adubo, a ureia, a semente, mais lona para canteiro, o veneno, as máquinas para passar veneno, tudo, e você vai pagar quando colhe. Tu não investe, tu não tem que puxar o dinheiro. Com o milho, tu tem que comprar a semente, adubo, ureia, comprar tudo. Depois, se der, tu vai ganhar; se não der, tu não vai ganhar nada. Não tem um seguro agrícola, não tem nada. Já com o fumo, já vem assegurado da firma (D. D., 46 anos).

Não é melhor a gente pegar, abandonar tudo e se mandar? Quem é que vai fazer? Dentro de uma família quantos que trabalham? Às vezes são duas pessoas. Como é que vai fazer? Tem que ficar em cima o ano todo, um mês, dois ou três, e como eliminar nos lugares onde não tem acesso? (J. R., 60 anos).

No começo muita gente queria sair daqui, mas é difícil vender a terra. [...] É muito trabalho! (C. G., 36 anos).

As lesmas representaram também uma saída utilizada por um morador para evitar um con- 
flito entre o seu vizinho e a empresa fornecedora de insumos para o seu aviário:

Eles pegavam no nosso pé porque o vizinho ali de cima tem galinha caipira e tava dando oxidiose nos frangos, que é uma doença de galinha caipira. E, nos aviários, os frangos são mais frágeis. Eles pegaram no nosso pé porque os veterinários queriam que a gente eliminasse as galinhas do vizinho. Mas não é bem assim! Imagine eu vou arrumar uma encrenca com o vizinho! Nunca! O vizinho, na hora do primeiro socorro, é quem me ajuda, não tem como brigar por causa das galinhas. [...] Um pouco pode ser, mas depois eu levantei a hipótese de que poderia ser das lesmas que vão na água. Daí eles não incomodaram mais. [...] E eu acho que foi mesmo, porque depois diminuiu as lesmase o problema no aviário (L. M., 34 anos).

\section{Medidas preventivas, percepção de risco e mudança de hábitos}

As medidas descritas pelos entrevistados seguem dois padrões: aquele sugerido pelo médico, que inclui recomendações para lavar bem as frutas e verduras, não mascar capim, não usar lesmas como iscas para pescaria e no final da pesquisa proteger os poços de água e aquele identificado e utilizado, ao longo dos anos, pela própria comunidade, que inclui o uso de cal, sal, veneno. Entre as mudanças de hábitos alimentares, destacam-se o consumo de carne bem assada e a diminuição do consumo de verduras ou seu consumo somente quando provenientes de outras regiões.

Nas reuniões com a comunidade, a equipe de pesquisadores alertava que, enquanto as lesmas existissem, todos deveriam ferver os alimentos, mas que a alface não deveria ser evitada. Deveriam lavar e examinar cada folha para evitar o risco da ingestão de lesmas ou de seus resíduos. Também se recomendou colocar as verduras em um litro de água com uma colher de QBoa durante meia hora. Em seguida, elas deveriam ser lavadas, de preferência, em água corrente. O médico enfatizava esse procedimento por ser um recurso recomendado também para prevenir o cólera.

As medidas preventivas recomendadas pelo médico foram assim assimiladas:

Não andar descalço, limpar o que se come, principalmente as verduras, não comer fruta com casca (J. P., 35 anos).

Nós temos um poço bem encamisado. Por medo, nós colocamos uma camada dupla e fizemos uma chapa de concreto em cima, mas eles disseram que elas passam em qualquer buraquinho. [...] Eu fervo o leite de noite e ponho a tampa na leiteira. A chaleira eu também deixo sempre seca de noite e de manhã eu dou várias enxaguadas (L. F., 42 anos).

As medidas preventivas identificadas e executadas pela própria comunidade incluíram procedimentos tais como utilização de veneno, sal e cloro:

O hábito das lesmas dificulta eliminar. Se fosse um inseto seria mais fácil, com inseticida tu elimina. O problema é que como ela se enfia em qualquer lugar, é difícil localizar e aplicar veneno (L. R., 63 anos).

Colocar veneno não resolve porque elas estão em todo lugar. Vai ter que colocar até dentro de casa (M. P., 38 anos).

No começo não se comia mais direito. A gente pensava que em todo tipo de comida podia ter. A criação de gado também podia estar comendo a lesma. A solução era assar bem a carne (D. D., 45 anos).

\section{Estigma e preconceito}

O impacto da doença teve vários momentos, desde o período inicial da coleta de sangue, quando o resultado era esperado com medo e no qual identificamos modificações comportamentais da população, até após os resultados da terceira coleta de sangue, na qual a doença já não significava um problema de saúde. A modificação no padrão de percepção da doença deve-se ao fato da não ocorrência de casos agudos ou graves.

Quanto à pesquisa médica, apesar das críticas, a maioria dos entrevistados a consideraram importante, embora ressaltassem que o problema das lesmas permanecia, bem como o preconceito por parte de pessoas de fora da comunidade. A linguagem técnica utilizada pelos pesquisadores durante as palestras também foi questionada. A distância entre o conhecimento médico e o conhecimento leigo fazia com que muitos termos não fossem compreendidos.

Por ocasião da primeira coleta de sangue, os moradores da região atingida mostravam-se preocupados. A reação, ao receberem os resultados, era de ansiedade e nervosismo, pois, além do seu próprio diagnóstico, as pessoas ficavam sabendo quem estava contaminado ou não. Muitas vezes, a mãe e o pai tinham resultado negativo e o(a) filho(a) tinha positivo ou vice-versa. Eles não compreendiam como isso poderia acontecer, uma vez que todos moravam na mesma casa e alimentavam-se da mesma maneira. Inicialmente, foi difícil para eles compreenderem e construí- 
rem uma explicação sobre a forma de contaminação e quais os comportamentos de risco. $\mathrm{Na}$ segunda coleta, talvez por causa dessas dúvidas e por medo, mais pessoas dispuseram-se a realizar o exame de sangue. Na primeira foram 114 indivíduos e, na segunda, 137. Alguns membros da comunidade mencionaram que o número só não era maior porque no dia e horário da coleta houve uma romaria realizada pela igreja local.

Até a segunda coleta constatou-se, por um lado, preocupação e nervosismo e, por outro, interesse e motivação da população em colaborar com os pesquisadores. Esse comportamento mudou nas outras duas coletas. Apesar da adesão ao estudo sorológico, a população estava receosa desde o início, e a pergunta que sempre surgia era: "Se a doença não tem tratamento, por que precisamos tirar sangue?”. Concordavam em realizar o exame porque queriam saber se estavam contaminados, mas, ao mesmo tempo contestavam a necessidade de realizar quatro coletas. Talvez o problema mais importante e mais enfatizado pelos entrevistados seja o decorrente da divulgação da contaminação em moluscos e na população daquela região. Os residentes perceberam que o valor econômico e simbólico de suas terras e a venda de alguns produtos decaíam. Um exemplo foi a proibição da compra de hortaliças da região, recomendada pelo Centro de Saúde e por algumas creches da cidade vizinha de Chapecó.

Aliado ao prejuízo econômico houve o preconceito surgido contra os residentes. Muitos entrevistados relataram que o comparecimento de pessoas de outras regiões às festas realizadas no Centro Comunitário reduziu-se por medo: Muitos diziam que as lesmas podem se grudar na roda dos seus carros, levando elas para suas casas. Além desse preconceito externo houve o interno, a partir do momento em que foi divulgado pela imprensa que o primeiro foco de lesmas teria ocorrido em 1993, com a vinda de mudas de árvores frutíferas de São Paulo. A comunidade imediatamente reconheceu quem havia trazido. O próprio morador, em entrevista, relatou a discriminação imediata que sofreu.

O diálogo entre dois moradores é ilustrativo:

Na última festa o pessoal disse: aquela alface de Cambucica eu não quero (G. T., 36 anos).

Hoje, se a gente quiser vender uma propriedade, ela não vai ter valor nenhum. Um cara como eu sabe que se tem lesma ninguém vai querer. Eu sou um que, se viesse aqui comprar, e soubesse das lesmas, eu não compraria! (D. L., 49 anos).

Outro diálogo, entre pai e filho, também traduz o preconceito:
Pai: Não ouvi comentário de que não viriam nas nossas festas ou de almoçar na casa de fulano porque ele estava contaminado... (J. R., 60 anos).

Filho: Mas com certeza tem alguém! (C. R., 21 anos).

Pai: Ah! pode ter, mas o que a gente faria? Teria medo também! (J. R., 60 anos).

Além destes, outros entrevistados relataram algum tipo de preconceito externo:

As pessoas deixaram de comprar as coisas. As verduras ninguém mais quer comprar daqui. Têm medo de pegar e levar a lesma (D. G., 34 anos).

Às vezes vem gente e não querem beber água daqui e nas festas trazem as verduras de fora... (N. L., 47 anos).

Eu vendo melancia, tomate, cebola, melão, repolho, pepino; só que não podia dizer que era da Cumbucica. Até hoje é assim! O pessoal de Nova Erechim, Chapecó, Itaberaba perguntavam de onde eram as verduras, e eu dizia que eram de Caxambu (D. D., 46 anos).

Um momento importante ocorreu quando uma das pessoas entrevistadas, ao ser abordada sobre o problema do preconceito, questionou a pesquisadora:

Eu acredito que a senhora já lavou as mãos várias vezes hoje! (L. F., 36 anos).

Para caracterizar o problema do preconceito interno, o diálogo entre um marido e a esposa é ilustrativo:

Marido: Eu não quero mais saber! Se amanhã tiver reunião [com o médico] eu não vou. Eu digo a verdade! Nós fomos muito discriminados, ninguém vinha aqui porque tinha lesma e podia levar para casa (M. P., 38 anos).

Esposa: Eles falavam que nós éramos relaxados, que nós não limpávamos a casa, que as crianças brincavam no meio da capoeira. Chegou num ponto que a gente ficava nervosa e revoltada com isso. E ninguém fez nada para ajudar. Quando começou a aparecer nas lavouras deles, daí começaram a ficar preocupados (L. P., 40 anos).

Marido: Um dia veio o L. com uns caras da RBS/ TV; aquele dia eu estourei! Eu disse: "Por favor, podem parar!" Eles encostaram a camionete, a moça já queria me pedir uma entrevista, outro já foi me focando e eu disse: "Pode parar!" [...] Eu disse: "Eu não vou dar nenhuma entrevista. Se vocês quiserem focalizem as lesmas, se quiserem falar, falam da comunidade da Cambucica, agora não divulguem que é na minha propriedade" (M. P., 38 anos).

Outros entrevistados revelaram a existência de algum tipo de preconceito interno:

Teve brincadeiras com quem tinha o verme. Mas o que vale é a consciência da pessoa. Eu disse 
para mim mesmo: eu não vou me preocupar com essa doença (G. T., 36 anos).

Muitos não queriam fazer o exame por medo de ser "gozado" pelos outros (G. T., 36 anos).

No começo teve preconceito, que nem no caso daquele contaminado e no meu caso, que deu duas vezes positivo... Mas a pessoa tem que reagir! (J. R., 60 anos).

\section{Considerações finais}

A explosão populacional de Sarasinula linguaeformis, inadvertidamente introduzida no sul de Santa Catarina, provocou um impacto inicial sobre os cultivos da região. Os prejuízos financeiros não foram estimados nem ressarcidos. Além disso, as lesmas são hospedeiros intermediários de um helminto que pode provocar infecções inaparentes ou clinicamente detectáveis no homem. Seu diagnóstico é difícil e foi necessário repetir exames sorológicos para ajustar a titulação, o que terminou por provocar reações negativas dos moradores, que não compreendiam sua necessidade, ainda mais que a doença não tinha tratamento. As comunidades vizinhas passaram a discriminar os indivíduos e os produtos originários da região afetada. As terras desvalorizaram-se e diversas famílias abandonaram sítios e fazendas.

A presença de um sociólogo na equipe de campo permitiu revelar ou ressaltar aspectos da pesquisa epidemiológica e agronômica que raramente são aparentes ou considerados. As informações e explicações dadas à população nem sempre são claramente entendidas, e as necessidades da pesquisa nem sempre são compreendidas e aceitas. As falas dos entrevistados ilustram bem os dramas familiares e pessoais.

Quanto ao teste sorológico utilizado ${ }^{22}$, que serve de parâmetro para definir o estatuto do normal e do patológico, é pertinente resgatar as contribuições de Canguilhem ${ }^{23}$, especialmente quanto à arbitrariedade na atribuição de uma média quando ela pressupõe uma validade universal. Como os resultados dos testes demonstraram uma variação muito grande e muitos indivíduos pertenciam a limiares muito próximos da linha de demarcação (cut off), o próprio médico sugeriu a elevação do padrão de referência para enquadrar os indivíduos com títulos sorológicos de 0.9 ou de 1.1 , já que acima do padrão 1.0 os indivíduos eram considerados infectados.

Os problemas decorrentes são: de que forma as mudanças provocadas pela elevação do cut off podem modificar para mais ou para menos o estatuto de normal e patológico ou, no caso desta pesquisa, de positivo ou negativo? Qual o impacto, no nível sociocultural, das alterações nesses coeficientes que caracterizam a doença e os doentes? Mais especificamente, qual o seu significado respectivamente para a medicina e para a população? Se para a ciência, e a pesquisa médica em particular, a alteração nesses percentuais significa apenas medidas técnicas e objetivas, para a população eles representam uma fonte de novas situações subjetivas e de problemas socioeconômicos.

Após o término da pesquisa soroepidemiológica, o próprio médico reconheceu que, para a população, tratava-se de uma doença criada por ele, ou seja, ela já existia para a ciência, mas não para a população: após a terceira coleta de sangue, a doença já não significava problema. Contudo, as lesmas como praga agrícola e as consequências da divulgação dos dados da pesquisa ainda são visíveis. Por isso salientamos e reforçamos a importância e a necessidade da presença de sociólogos e antropólogos nas equipes de pesquisas médicas e epidemiológicas, para que esses problemas possam ser identificados, evitados ou atenuados.

Os artigos analisados mencionaram a distribuição dos casos no país, indicando alguns estados brasileiros onde foi detectada a doença. Porém, com as análises das pesquisas de GraeffTeixeira ${ }^{5,13-18}$, ressalta-se hipótese do subdiagnóstico dessa patologia na medida em que pouco esforço científico e de vigilância tem sido realizado para detectar sistematicamente a sua ocorrência, bem como o seu caráter negligenciado no interior das políticas de saúde.

Apesar de a angiostrongilíase não constituir, até o momento, um problema de saúde pública, e não se possa avaliar sua prevalência e incidência, é interessante discutir como se dá a aplicação do conhecimento científico nas práticas institucionais, especialmente nos serviços de vigilância epidemiológica. Um ano após a pesquisa realizada na Linha Cumbucica, grande parte do litoral catarinense sofreu o ataque do molusco Achatina fulica, o caramujo-africano. Conforme o fôlder divulgado pela Vigilância Ambiental e Epidemiológica da Secretaria de Estado de Saúde de Santa Catarina, "ele foi introduzido no Brasil para substituir o escargot. Pode transmitir duas espécies de vermes: Angiostrongylus costaricensis e Angiostrongylus cantonensis". Contudo, não há relato de pesquisas que tenham averiguado se os moluscos estavam, de fato, contaminados, o que ocasionou problemas como a redução no fluxo turístico em algumas localidades e pânico na população. 
Em decorrência disso, é importante ressaltar o papel das análises socioantropológicas nas pesquisas sobre as endemias, as quais, geralmente, limitam-se ao estudo dos aspectos médicos e epidemiológicos dos problemas. Como observamos, muitos outros fatores estão envolvidos no processo de elucidação do ciclo do parasita e da doença e nas consequências do processo de tomada de decisões institucionais. Isso ficou evidente quando analisamos como a população pesquisada percebeu e reagiu diante das consequências da identificação da presença do parasito na região e da contaminação humana.

\section{Colaboradores}

\section{Referências}

M Grisotti e FD Ávila-Pires participaram igualmente de todas as etapas da elaboração do artigo.

1. Elton C. The ecology of invasions by animals and plants. Methuen: London; 1958.

2. Bates M. Man as an agent in the spread of organisms. In: Thomas Jr., WL., editores, Man's role in changing the face of the Earth. Chicago: University of Chicago Press; 1956. p. 788-804.

3. Crosby AW. Germs, seeds \& animals: studies in ecological history. Sharpe: Amonk; 1984.

4. Crosby AW. Ecological imperialism: the biological expansion of Europe, 900-1900. Cambridge: Cambridge University Press; 1986.

5. Laitano AC, Genro JP, Fontoura R, Branco SS, Maurer RL, Graeff-Teixeira C, Milanez JM, Chiaradia LA, Thomé JW. Report on the occurrence of Angiostrongylus costaricensis in Southern Brazil, in a new intermediate host from the genus Sarasinula (Veronicellidae, Gastropoda). Rev Sociedade Brasileira de Medicina Tropical 2001; 34(1):95-97.

6. Morera P, Céspedes R. Angiostrongylus costaricensis $n$, sp. (Nematoda: Metastrongyloidea), a new lungworm occurring in man in Costa Rica. Revista de Medicina Tropical 1970; 18(1):173-185.

7. Céspedes R, Salas J, Mekbel S, Troper L, Mullner F, Morera P. Granulomas entéricos y linfáticos com intensa eosinofilia tisular producidos por un estrongilídeo (Strongylata). Acta Médica Costarricense 1967; 10:235-255.

8. Morera P, Cespedes R. Angiostrongilosis abdominal: una nueva parasitosis humana. Acta Médica Costarricense 1971; 14:159-173.

9. Moro L, Hemp S. Ocorrência de lesmas na região oeste catarinense. In: Resumos do Encontro Brasileiro de Malacologia, $14^{\circ}$ Congresso Latino-Americano de Malacologia, $2^{a}$ Feira Internacional sobre Moluscos, $1^{a}$ Reunião Nacional dos Conquiliologistas. Porto Alegre: PUC/SBMa/CP-Clama; 1995. p. 106.

10. Lesmas - mais uma praga? Jornal Agropecuária Catarinense 1995; 8(2):16. 
11. Chiaradia LA, Milanez JM. Lesmas: rastejante, nojenta e perigosa. Revista Cultivar 1999; 1(5):16-17.

12. Thomé JW. Estado atual da sistemática dos Veronicellidae (Molusca; Gastropoda) americanos, com comentários sobre sua importância econômica, ambiental e na saúde. Biociências 1993; 1(1):61-75.

13. Graeff-Teixeira C. Estudos sobre Angiostrongilíase abdominal no sul do Brasil [dissertação]. Rio de Janeiro: Universidade Federal do Rio de Janeiro; 1986.

14. Graeff-Teixeira C. Contribuição ao conhecimento da epidemiologia da angiostrongilíase abdominal no sul do Brasil [tese]. Rio de Janeiro: Instituto Oswaldo Cruz; 1991.

15. Graeff-Teixeira C, Camillo-Coura L, Lenzi HL. Abdominal Angiostrongyliasis: an under-diagnosed disease. Mem Inst Oswaldo Cruz 1987; 82 (Supl.IV):353-354.

16. Graeff-Teixeira C, Camillo-Coura L, Lenzi HL. Clinical and epidemiological aspects of abdominal angiostrongyliasis in Southern Brazil. Revista do Instituto de Medicina Tropical de São Paulo 1991; 33(5):373378 .

17. Graeff-Teixeira C, Thiengo SC, Thomé JW, Medeiros AB, Camillo-Coura L, Agostini AA. On the diversity of mollusc intermediate hosts of Angiostrongylus costaricensis Morera \& Céspedes, 1971 in Southern Brazil. Mem Inst Oswaldo Cruz 1993; 88(3):487-489.

18. Graeff-Teixeira C, Rambo PR, Agostini AA. Abdominal angiostrongylosis in Southern Brazil: prevalence and parasitic burden in mollusc intermediate hosts from eighteen endemic foci. Mem Inst Oswaldo Cruz 1997; 92(1):9-14.

19. Proliferação de lesmas é investigada no Oeste. Diário Catarinense 2000; 15 ago. p. 21 (destaque em capa).

20. Melhor equipe de pesquisadores do Brasil estuda em Nova Itaberaba impacto ambiental do ataque das lesmas. Cooperalfa 2001; 145:17.

21. Goffman E. Stigma: notes on the management of spoiled identity. London: Prentice-Hall; 1963.

22. Graeff-Teixeira A, Camillo-Coura L, Ferreira-daCruz MF. Seroepidemiology of abdominal angiostrongyliasis: the standardization of an immunoenzymatic assay and prevalence of antibodies in two localities in Southern Brazil. Tropical Medicine and International Health 1997; 2(3):254-260.

23. Canguilhem G. Le normal et le pathologique. Paris: P.U.F.; 1996.

Artigo apresentado em 18/10/2007

Aprovado em 02/07/2008

Versão final apresentada em 06/08/2008 